\title{
Modeling of predissection aortic size in acute type A dissection: \\ More than $90 \%$ fail to meet the guidelines for elective ascending replacement
}

\author{
Bartosz Rylski, MD, a,b Emanuela Branchetti, PhD, ${ }^{a}$ Joseph E. Bavaria, MD, ${ }^{a}$ \\ Prashanth Vallabhajosyula, MD, ${ }^{a}$ Wilson Y. Szeto, MD, ${ }^{\mathrm{a}}$ \\ Rita K. Milewski, MD, PhD, ${ }^{a}$ and Nimesh D. Desai, $\mathrm{MD}, \mathrm{PhD}^{\mathrm{a}}$
}

\begin{abstract}
Objectives: The current guidelines for ascending aortic replacement were determined from already dissected aorta diameters. Previous computed tomography-based work on humans who underwent imaging before and directly after aortic dissection onset has shown an average 30\% increase in the ascending aortic diameter with acute dissection. The present investigation evaluated the incidence of predissection ascending aortic dilatation in acute type A dissection.
\end{abstract}

\begin{abstract}
Methods: From 2002 to 2013, 495 patients presented with acute type A aortic dissection to 1 center. Of these cases, 343 were non-Marfan, nonbicuspid with spontaneous dissection etiology. In those with available preoperative computed tomography angiograms $(n=83)$ or transesophageal echocardiograms $(n=260)$, the predissection ascending aorta diameters were modeled from the dissected aorta diameters by subtraction of the average diameter increase rate.
\end{abstract}

Results: Altogether 343 patients were included (age, 62 years; range, 53-73; 64\% men). The median modeled predissection ascending diameter was $3.7 \mathrm{~cm}$ (first quartile, 3.3; third quartile, -4.1 ). Of the 343 patients, 334 $(97 \%)$ and $315(92 \%)$ had an ascending diameter before dissection onset of $<5.5 \mathrm{~cm}$ and $<5.0 \mathrm{~cm}$, respectively. More than $60 \%$ of women and $70 \%$ of men had a nondilated ascending aorta before type A dissection onset. The median predissection ascending aortic diameter did not differ between women and men $(3.7 \mathrm{~cm}$; first quartile, 3.4 ; third quartile, 4.2 ; vs $3.7 \mathrm{~cm}$; first quartile, 3.3 ; third quartile, $4.1 ; P=.810$ ).

Conclusions: More than $60 \%$ of patients with spontaneous, non-Marfan, nonbicuspid, type A dissection will have a nondilated ascending aorta before dissection onset. Only 3\% would meet the criteria for elective ascending replacement to prevent aortic dissection. Additional research on the genetic and biochemical predictors of aortic dissection is essential. (J Thorac Cardiovasc Surg 2014;148:944-8)

Supplemental material is available online.

The current guidelines for ascending aortic replacement were determined from the diameters of already dissected aortas. ${ }^{1-3}$ Previous computed tomography (CT)-based work on humans who had undergone imaging done before

\footnotetext{
From the Division of Cardiovascular Surgery, ${ }^{\mathrm{a}}$ Hospital of the University of Pennsylvania, Philadelphia, Pa; and Heart Center, ${ }^{\mathrm{b}}$ University of Freiburg, Freiburg, Germany.

Disclosures: Authors have nothing to disclose with regard to commercial support.

Read at the 94th Annual Meeting of The American Association for Thoracic Surgery, Toronto, Ontario Canada, April 26-30, 2014.

Received for publication March 18, 2014; revisions received May 14, 2014; accepted for publication May 19, 2014; available ahead of print July 4, 2014.

Address for reprints: Bartosz Rylski, MD, Heart Center Freiburg University, Hugstetter Str. 55, 79106 Freiburg, Germany (E-mail: bartosz.rylski@ universitaets-herzzentrum.de).

$0022-5223 / \$ 36.00$

Copyright (c) 2014 by The American Association for Thoracic Surgery

http://dx.doi.org/10.1016/j.jtcvs.2014.05.050
}

and directly after aortic dissection onset showed an average $30 \%$ increase in the ascending aortic diameter with acute dissection. ${ }^{4}$ Therefore, because to date, all reports on the ascending diameter in patients with acute type A dissection have presented the diameter of the dissected aorta, it is conceivable that the true incidence of predissection ascending dilatation has been greatly overestimated.

The aim of the present study was to evaluate the incidence of ascending aortic dilatation in the acute type A dissection population according to the modeled predissection aortic diameters.

\section{METHODS}

\section{Study Population, Design, and Definitions}

From 2002 to 2013, 495 patients underwent surgery for acute Stanford type A aortic dissection. Included in the present analysis were those patients with non-Marfan and nonbicuspid aortic dissection. For those with available preoperative CT angiograms (CTAs, $\mathrm{n}=83$ ) or transesophageal echocardiograms (TEEs, $n=260$ ), the predissection ascending aorta diameters were modeled from the dissected aorta diameters by subtraction of the average diameter increase rate (30\%) according to results of a study of humans on aortic geometry changes due to dissection. ${ }^{4}$ The aortic diameters 

Abbreviations and Acronyms
BSA $=$ body surface area
$\mathrm{CT}=$ computed tomography
$\mathrm{CTA}=$ computed tomography angiogram
TEE $=$ transesophageal echocardiogram

were measured using true centerline measurements from the CTAs or averaged from multiple in-plane measurements from the TEEs. The variation in the measured diameters on the CTAs and TEEs (both available for 48 patients) ranged from 0 to $5 \mathrm{~mm}$. In later study years, the use of multiplane TEE and 3-dimensional TEE became more common. The largest diameter present between the aortic valve plane and innominate artery was used. The modeled predissection ascending diameters were compared between men and women in 4 age categories ( $<45,45-54,55-64$, and $>64$ years) and sex-specific, age- and body surface area (BSA)-adjusted normal values (Table E1) defined in a study of 2952 patients. ${ }^{5}$

Acute aortic dissection was defined as dissection operated on no later than 14 days after symptom onset. The institutional review committee approved the present retrospective study, and the need for informed consent was waived.

\section{Statistical Analysis}

The statistics are presented as frequencies and percentages for categorical variables and as the median and first and third quartiles for continuous variables, because the variables were not all normally distributed according to the Kolmogorov-Smirnov test. For comparison of the continuous variables, the Mann-Whitney rank sum test was used. Categorical variables were compared using the chi-square test. In the case of small group sizes $(n<5)$, Fisher's exact test was used. The association of the modeled ascending aortic diameter with age and BSA was tested using linear regression models in each sex. All statistical calculations were performed using SigmaPlot, version 12 (Systat Software, San Jose, Calif).

\section{RESULTS}

\section{Baseline Characteristics}

Overall, 343 patients were included in the present study (123 women and 220 men). The baseline characteristics are listed in Table 1. Acute type A aortic dissection occurred in women at an older age than in men (median, 67 years; first quartile, 56; third quartile, 77; and median, 59 years; first quartile, 50; third quartile, $71 ; P<.001$ ). The cardiovascular risk profile did not significantly differ between both sexes.

\section{Modeled Predissection Ascending Diameter}

The median diameter of the dissected ascending aorta was $4.9 \mathrm{~cm}$ (first quartile, 4.4; third quartile, 5.5 ). The median estimated predissection ascending diameter was 3.7 $\mathrm{cm}$ (first quartile, 3.3; third quartile, 4.1) and did not differ between the sexes in the different age categories (Table 1). The diameter of the dissected ascending aorta was $<5.5 \mathrm{~cm}$ in 237 patients $(69 \%)$ and $<5.0 \mathrm{~cm}$ in 178 patients $(52 \%)$. Analysis of the estimated predissection ascending diameter revealed that 334 of the 343 patients $(97 \%)$ had an ascending diameter before dissection onset that was less than the threshold value for prophylactic ascending replacement $(<5.5 \mathrm{~cm})$ and $325(92 \%)$ had an ascending diameter of $<5.0 \mathrm{~cm}$ (Figure 1).

The modeled predissection ascending diameter was similarly associated with age in both sexes (women, $r=.20$, $P=.030$; men, $r=.18, P=.007)$. No significant correlation was found between the ascending aorta diameter and BSA (women, $P=.466$; men, $P=.066$; Figure 2).

\section{Predissection Ascending Diameter Versus Normal Reference Diameter}

The distribution of the modeled predissection ascending diameter for both sexes and the different age and BSA categories compared with the normal reference diameters is shown in Figure 3. Overall, $63 \%$ of women and $74 \%$ of men had a normal (nondilated) ascending aorta before type A dissection onset (Figure 4). Among patients aged

TABLE 1. Clinical characteristics and aortic predissection diameters

\begin{tabular}{|c|c|c|c|c|}
\hline Variable & All $(n=343)$ & Women $(\mathbf{n}=123)$ & $\operatorname{Men}(\mathbf{n}=220)$ & $P$ value \\
\hline Age (y) & $62(53 ; 73)$ & $67(56 ; 77)$ & $59(50 ; 71)$ & $<.001$ \\
\hline BMI $\left(\mathrm{kg} / \mathrm{m}^{2}\right)$ & $28.1(25.6 ; 32.0)$ & $27.3(23.2 ; 33.8)$ & $28.3(25.6 ; 32.0)$ & .396 \\
\hline $\operatorname{BSA}\left(\mathrm{m}^{2}\right)$ & $1.99(1.83 ; 2.17)$ & $1.83(1.64 ; 1.96)$ & $2.09(1.95 ; 2.21)$ & $<.001$ \\
\hline Hypertension & $295(86)$ & 109 (89) & $186(85)$ & .379 \\
\hline Diabetes & $36(10)$ & $17(14)$ & $19(9)$ & .165 \\
\hline History of stroke & $28(8)$ & $13(11)$ & $15(7)$ & .312 \\
\hline COPD & $40(12)$ & $19(15)$ & $21(10)$ & .127 \\
\hline Coronary artery disease & $54(16)$ & $23(19)$ & $31(14)$ & .173 \\
\hline Previous cardiac surgery & $29(9)$ & $10(8)$ & $19(9)$ & .968 \\
\hline \multicolumn{5}{|c|}{ Predissection ascending aortic diameter $(\mathrm{cm})$} \\
\hline \multicolumn{5}{|l|}{ Age category } \\
\hline$<45 \mathrm{y}$ & $3.4(3.2 ; 3.8)$ & $3.3(3.1 ; 3.6)$ & $3.4(3.2 ; 4.0)$ & .177 \\
\hline $45-54$ y & $3.6(3.2 ; 4.1)$ & $3.5(3.1 ; 3.9)$ & $3.7(3.3 ; 4.1)$ & .318 \\
\hline $55-64$ y & $3.6(3.3 ; 4.1)$ & $3.6(3.3 ; 4.2)$ & $3.6(3.3 ; 3.9)$ & .589 \\
\hline$>64 y$ & $3.8(3.4 ; 4.4)$ & $3.8(3.5 ; 4.5)$ & $3.9(3.4 ; 4.3)$ & .985 \\
\hline Overall & $3.7(3.3 ; 4.1)$ & $3.7(3.4 ; 4.2)$ & $3.7(3.3 ; 4.1)$ & .810 \\
\hline
\end{tabular}

Data presented as median (first quartile; third quartile) or $\mathrm{n}(\%) . B M I$, Body mass index; $B S A$, body surface area; COPD, chronic obstructive pulmonary disease. 




Post-dissection diameter $n=343$

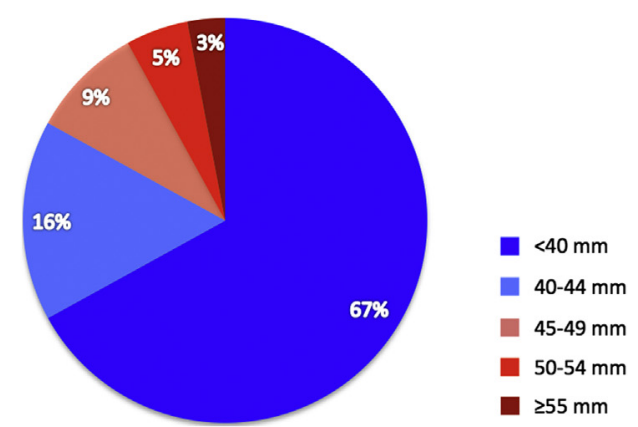

Modeled pre-dissection diameter $n=343$

Ascending Aorta

FIGURE 1. Distribution of postdissection and modeled predissection ascending aortic diameter in patients with acute type A aortic dissection.

55 to 64 years, a tendency was seen toward a greater rate of nondilated ascending aortas in men than in women $(83 \%$ vs $66 \%, P=.117)$.

\section{DISCUSSION}

The findings of the present study can be summarized as follows. First, $>90 \%$ of patients presenting with acute type A aortic dissection would fail to meet the guidelines for elective ascending replacement before dissection onset. Second, most patients with non-Marfan, tricuspid aortic valve who develop type A aortic dissection will have a normal, nondilated ascending aorta. Finally, the ascending aorta will dissect at the same average diameter in both sexes.

Several reports have been published on the ascending aortic diameter in patients with acute type A dissection. . $^{6-8}$ Usually, the average ascending diameter has been reported to be about $5 \mathrm{~cm}$, with the diameter range spanning those with a nondilated aorta to those with huge aneurysms. However, all studies to date have assessed already dissected aortas. However, other reports have shown that the diameter of the dissected aorta differs from that of the same nondissected aorta. ${ }^{9,10}$ Recently, we quantified the extent of these changes in the human ascending aorta using CTAs obtained before and after acute aortic dissection type $\mathrm{A} .{ }^{4}$ We found that the average diameter increase with acute dissection was $+32 \%{ }^{4}{ }^{4}$ From these findings, we modeled the predissection diameter by subtracting the average diameter increase from the dissected aorta diameter in a large cohort of patients with acute type A dissection. We observed that, not only in most patients was the dissected aorta diameter $<5.5 \mathrm{~cm}$, but also, almost all patients $(97 \%)$ had a predissection diameter of $<5.5 \mathrm{~cm}$; the threshold for prophylactic ascending replacement. However, our analysis included patients treated at a tertiary center. We would not expect a large number of patients to have a diameter $>5.5 \mathrm{~cm}$ at the moment of aortic dissection, because those patients with a diagnosed ascending aneurysm would have undergone elective surgery in accordance with the guidelines. However, no screening service for ascending aortic aneurysms is offered to the entire population in our region; therefore, the denominator of patients with ascending dilatation or aneurysm remains unknown.

Modeling the predissection diameter allowed us to identify patients with a nondilated ascending aorta before dissection onset. The frequency of this phenomenon was greater than expected. We showed that $63 \%$ of women and $74 \%$ of men had a normal (nondilated) ascending aorta before dissection. These findings underline the need for more powerful aortic event predictors than the diameter.
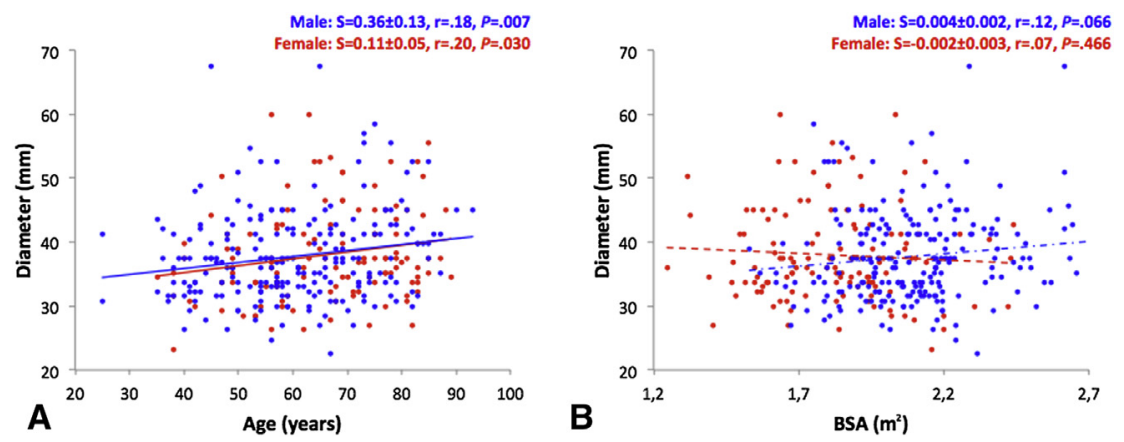

FIGURE 2. Sex-specific modeled predissection ascending aortic diameter in relation to (A) age and (B) body surface area (BSA). 


\section{Female}
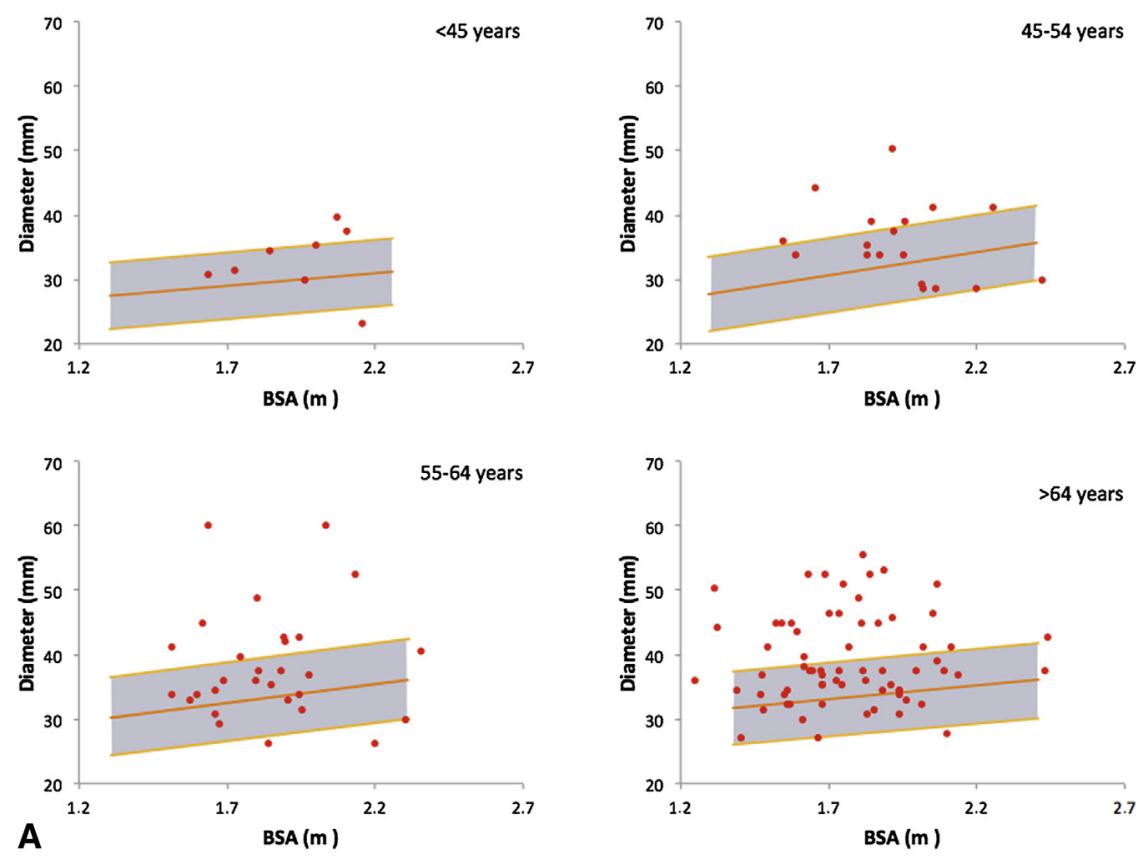

\section{Male}
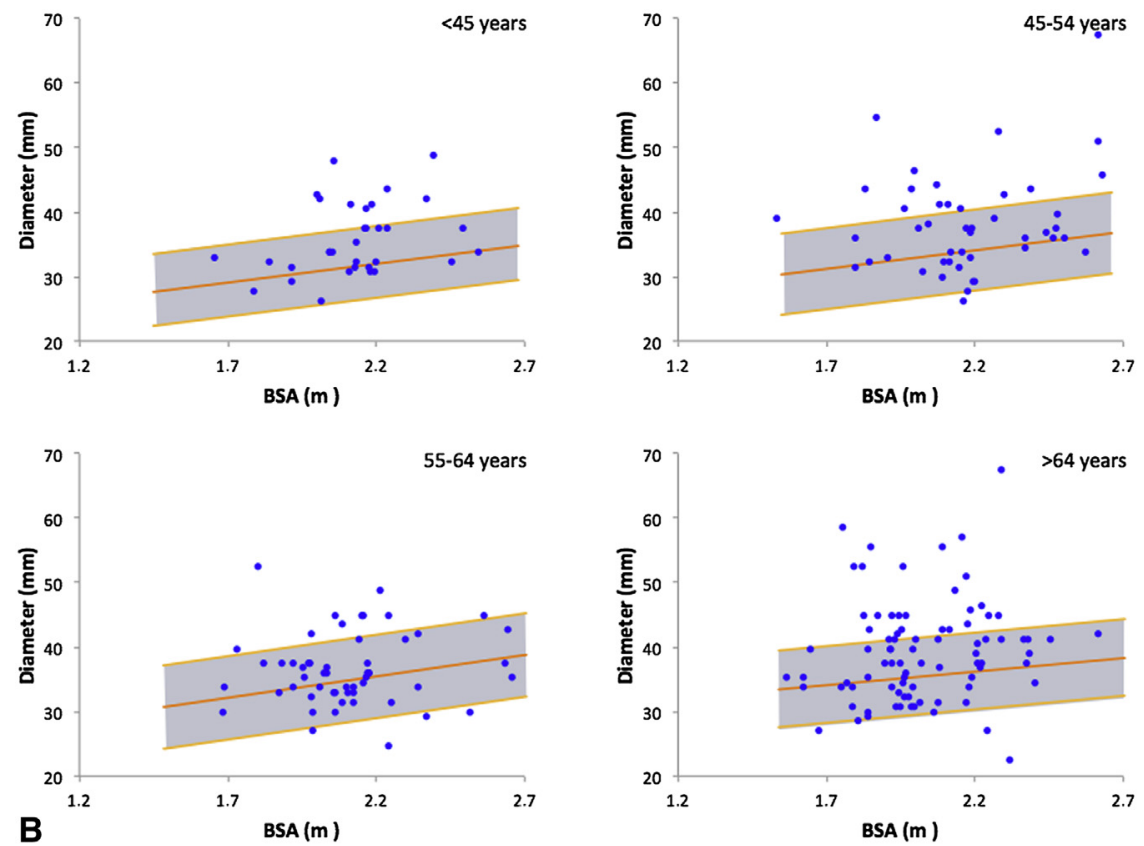

FIGURE 3. Distribution of modeled predissection ascending diameter in (A) women (red dots) and (B) men (blue dots) for different age and body surface area (BSA) categories. The orange lines represent the mean ascending aortic diameter; the yellow lines, the estimated $95 \%$ normal confidence limits according to the normal reference diameters. ${ }^{5}$

Currently, no single biomarker or established imaging marker, such as aortic wall stress or strain function, is available to positively predict aortic dissection. Our results strongly support the hypothesis that additional research on the genetic, biochemical, and imaging predictors of aortic dissection is essential.
Finally, the ascending aorta dissected at the same average diameter in both sexes. In most reports of type A aortic dissection, the dissection incidence was greater among men, with the average ratio of $3: 2 .^{11-14}$ The normal aortic diameter is greater in men. ${ }^{15,16}$ Because the aortic diameter before dissection in both sexes was similar, the 


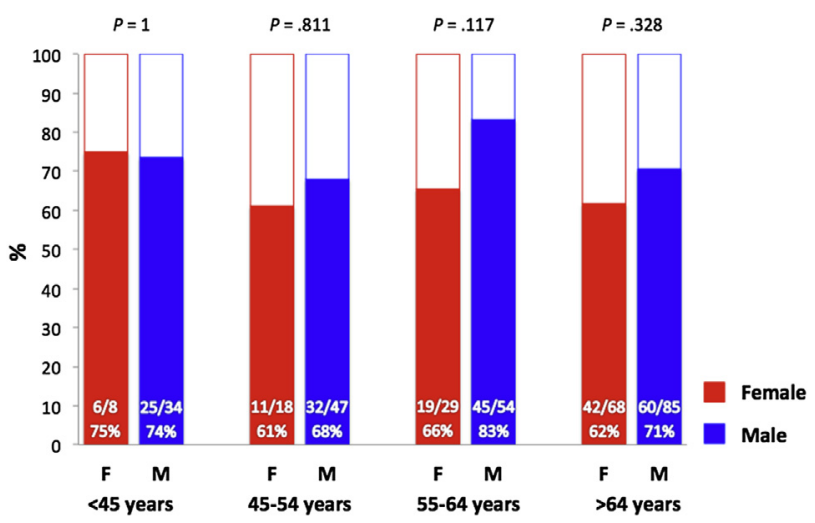

FIGURE 4. Sex-related incidence of nondilated ascending aorta in patients with acute type A aortic dissection. $F$, Female; $M$, male.

commonly smaller normal aortic dimensions in women might be protective against aortic dissection, explaining the observed lower incidence of type A dissection among women.

\section{Study Limitations}

Our study had 2 major limitations. First, the diameter increase due to dissection might differ among patients; however, the same average diameter increase was subtracted for all patients. Second, in most patients, the dissected ascending aorta diameter was obtained from the TEEs, but for the modeled predissection diameter, we referred to a CTA-based study. ${ }^{4}$

\section{CONCLUSIONS}

Modeling of the predissection ascending aortic geometry enabled us to predict the incidence of aortic dilatation in patients with acute type A dissection. More than $60 \%$ of patients with spontaneous, non-Marfan, nonbicuspid type A dissection had a nondilated ascending aorta before dissection onset. Only $3 \%$ would have met the criteria for elective ascending replacement to prevent aortic dissection. Additional research on the genetic, biochemical, and imaging predictors of aortic dissection is essential.

\section{References}

1. Hiratzka LF, Bakris GL, Beckman JA, Bersin RM, Carr VF, Casey DE Jr, et al. 2010 ACCF/AHA/AATS/ACR/ASA/SCA/SCAI/SIR/STS/SVM guidelines for the diagnosis and management of patients with Thoracic Aortic Disease: a report of the American College of Cardiology Foundation/American Heart Association Task Force on Practice Guidelines, American Association for Thoracic Surgery, American College of Radiology, American Stroke Association, Society of Cardiovascular Anesthesiologists, Society for Cardiovascular Angiography and Interventions, Society of Interventional Radiology, Society of Thoracic Surgeons, and Society for Vascular Medicine. Circulation. 2010; 121:e266-369.

2. Coady MA, Rizzo JA, Hammond GL, Kopf GS, Elefteriades JA. Surgical intervention criteria for thoracic aortic aneurysms: a study of growth rates and complications. Ann Thorac Surg. 1999;67:1922-6.

3. Davies RR, Goldstein LJ, Coady MA, Tittle SL, Rizzo JA, Kopf GS, et al. Yearly rupture or dissection rates for thoracic aortic aneurysms: simple prediction based on size. Ann Thorac Surg. 2002;73:17-27.

4. Rylski B, Blanke P, Beyersdorf F, Desai ND, Milewski RK, Siepe M, et al. How does the ascending aorta geometry change when it dissects? J Am Coll Cardiol. 2014;63:1311-9.

5. Wolak A, Gransar H, Thomson LE, Friedman JD, Hachamovitch R, Gutstein A, et al. Aortic size assessment by noncontrast cardiac computed tomography: normal limits by age, gender, and body surface area. JACC Cardiovasc Imaging . 2008;1:200-9.

6. Parish LM, Gorman JH III, Kahn S, Plappert T, St John-Sutton MG, Bavaria JE, et al. Aortic size in acute type A dissection: implications for preventive ascending aortic replacement. Eur J Cardiothorac Surg. 2009;35:941-6.

7. Pape LA, Tsai TT, Esselbacher EM, Oh JK, O'Gara PT, Evangelista A, et al. Aortic diameter $>5.5 \mathrm{~cm}$ is not a good predictor of type A aortic dissection: observations from the International Registry of Acute Aortic Dissection (IRAD). Circulation. 2007;116:1120-7.

8. Sütsch G, Jenni R, von Segesser L, Turina M. Predictability of aortic dissection as a function of aortic diameter. Eur Heart J. 1991;12:1247-56.

9. Okuno T, Yamaguchi M, Okada T, Takahashi T, Sakamoto N, Ueshima E, et al. Endovascular creation of aortic dissection in a swine model with technical considerations. J Vasc Surg. 2012;55:1410-8.

10. Neri E, Barabesi L, Buklas D, Vricella LA, Benvenuti A, Tucci E, et al. Limited role of aortic size in the genesis of acute type A aortic dissection. Eur J Cardiothorac Surg. 2005;28:857-63.

11. Rylski B, Hoffmann I, Beyersdorf F, Suedkamp M, Siepe M, Nitsch B, et al. Acute aortic dissection type A: age-related management and outcomes reported in the German Registry for Acute Aortic Dissection Type A (GERAADA) of over 2000 patients. Ann Surg. 2014;259:598-604.

12. Rylski B, Hoffmann I, Beyersdorf F, Suedkamp M, Siepe M, Nitsch B, et al. Iatrogenic acute aortic dissection type A: insight from the German Registry for Acute Aortic Dissection Type A (GERAADA). Eur J Cardiothorac Surg. 2013;44:353-9.

13. Song SW, Yoo KJ, Shin YR, Lim SH, Cho BK. Effects of intermittent lower body perfusion on end-organ function during repair of acute DeBakey type I aortic dissection under moderate hypothermic circulatory arrest. Eur J Cardiothorac Surg. 2013;44:1070-4.

14. Rylski B, Beyersdorf F, Blanke P, Boos A, Hoffmann I, Dashkevich A, et al. Supracoronary ascending aortic replacement in patients with acute aortic dissection type A: what happens to the aortic root in the long run? J Thorac Cardiovasc Surg. 2013;146:285-90.

15. Rylski B, Desjardins B, Moser W, Bavaria JE, Milewski RK. Gender-related changes in aortic geometry throughout life. Eur J Cardiothorac Surg. 2014;45: 805-11.

16. Mao SS, Ahmadi N, Shah B, Beckmann D, Chen A, Ngo L, et al. Normal thoracic aorta diameter on cardiac computed tomography in healthy asymptomatic adults: impact of age and gender. Acad Radiol. 2008;15:827-34. 
TABLE E1. Gender-, age-, and BSA-related ascending aortic diameter upper limits

\begin{tabular}{lccc}
\hline & & \multicolumn{2}{c}{ Ascending diameter $(\mathbf{m m})(\mathbf{n}=\mathbf{2 9 5 2})$} \\
\cline { 3 - 4 } Age $(\mathbf{y})$ & BSA $\left(\mathbf{m}^{2}\right)$ & Female & Male \\
\hline$<45$ & $<1.70$ & 33.8 & 33.0 \\
& $1.70-1.89$ & 34.4 & 36.3 \\
& $1.90-2.09$ & 35.0 & 36.3 \\
& $>2.1$ & - & 38.3 \\
$45-54$ & $<1.70$ & 35.2 & 38.6 \\
& $1.70-1.89$ & 37.2 & 38.1 \\
& $1.90-2.09$ & 38.9 & 39.7 \\
& $>2.1$ & 40.6 & 40.6 \\
$55-64$ & $<1.70$ & 36.9 & 36.3 \\
& $1.70-1.89$ & 37.0 & 39.7 \\
& $1.90-2.09$ & 39.0 & 41.2 \\
& $>2.1$ & 42.0 & 43.1 \\
$>64$ & $<1.70$ & 37.5 & 38.5 \\
& $1.70-1.89$ & 39.2 & 41.0 \\
& $1.90-2.09$ & 42.7 & 42.2 \\
& $>2.1$ & - & 42.4 \\
\hline
\end{tabular}

Data from Wolak and colleagues. ${ }^{5} B S A$, Body surface area. 